\title{
Northern Sami Language
}

National Cancer Institute

\section{Source}

National Cancer Institute. Northern Sami Language. NCI Thesaurus. Code C154119.

A Uralic Sami language spoken in the northern parts of Norway, Sweden, and Finland. 